\title{
PRACTICE-ORIENTED APPROACH USE FOR PROSPECTIVE DESIGNERS AND TEACHERS TRAINING AT HIGHER EDUCATIONAL ESTABLISHMENTS
}

(C) 2017

\author{
Ashutova Tatiana Vyacheslavovna, candidate of pedagogical sciences, \\ dean of Arts and Service Faculty \\ Murmansk Arctic State University (Murmansk, Russian Federation)
}

\begin{abstract}
This paper deals with the problem of results' quality improving in educational programs and their development in connection with the introduction of new higher education standards, which require the usage of a practice-oriented approach in training future designers and teachers. Topical aspects of competence model in training students majoring in «graphic design» are elucidated in the paper. A trend that traditional education is losing ground to practice-oriented education is also considered. The paper deals with basic modern approaches to understanding and defining the essence of practice-oriented learning. The author's vision of knowledge-oriented and practiceoriented approach balance (with regard to the educational specifics of teachers-designers) is presented. It describes the implementation of practice-oriented training in the internship of designers and teachers of Arts and Service Department at Murmansk Arctic State University. It is necessary to create methodological support of the training process according to the requirements of a practice-oriented training model. Pedagogical literature in training, analysis of state educational standards, modern approaches to the design and implementation of e-learning, own practical experience, description of the main provisions were used in the development of practice-oriented electronic textbook «Information technologies in graphic design». The paper depicts a basic method of practice-oriented learning that is implemented in educational practice at Arts and Service Department at MASU.

Keywords: competence; practice-oriented approach; knowledge; skill; experience activities; professional competence; teacher; designer; bachelor student; student; textbook; methods; tools; design; technology; pedagogical principles; activity principle; principle of modularity; principle of theory and practice connection.
\end{abstract}

УДК 378.14

\section{СИСТЕМА СКВОЗНЫХ ЗАДАЧ КАК УСЛОВИЕ ПРОФЕССИОНАЛЬНОЙ ОРИЕНТАЦИИ ОБУЧЕНИЯ СТУДЕНТОВ НАПРАВЛЕНИЯ «ПРИКЛАДНАЯ ИНФОРМАТИКА»}

(C) 2017

\author{
Васева Елена Сергеевна, кандидат педагогических наук, \\ доцент кафедры информационных технологий \\ Нижнетагильский государственный сочиально-педагогический институт \\ (филиал Российского государственного профессионально-педагогического университета) \\ (2. Нижний Тагил, Свердловская область, Российская Федерация)
}

Аннотация. Актуализируется применение в учебном процессе вузов системы сквозных задач как необходимого условия профессиональной направленности обучения. Применение системы сквозных задач способствует развитию целостного мышления у студентов, направлено на овладение способами действия в конкретной производственной ситуации. Представлен фрагмент разработанной автором системы сквозных задач, реализуемой в курсе «Предметно-ориентированные экономические информационные системы» для бакалавров направления «Прикладная информатика» профильной подготовки «Прикладная информатика в экономике». Курс состоит из нескольких модулей, описываемая система сквозных задач реализована в рамках модуля «Информационные системы управления персоналом». Пример системы содержит несколько «сюжетных» линий, демонстрирующих методики учета стандартных операций по ведению кадрового документооборота и управлению персоналом предприятия, расчету и выплате заработной платы в автоматизированной системе. На конкретных задачах продемонстрирована преемственность и связь в изучении всех разделов модуля. Обозначены трудности применения системы сквозных задач: строгая последовательность применяемой методики; расхождение в скорости выполнения заданий студентами; невозможность включить в систему задачи определенного вида; зависимость от результата, полученного на предыдущих занятиях. Для каждой из них определены возможные пути решения.

Ключевые слова: обучение; учебная дисциплина; система сквозных задач; системное восприятие; профессиональные компетенции; прикладной характер обучения; производственная ситуация; предметно-ориентированная экономическая информационная система; информационная система управления персоналом.

Постоянно обновляющийся поток информации, изменение нормативно-правового регулирования выдвигают все более высокие требования к уровню подготовки будущих выпускников вузов. В настоящее время основополагающими требованиями к уровню освоения основных образовательных программ является профессиональные компетенции [1; 2], реализация большей части которых достаточно проблематична без доминирующей роли прикладного, практического характера обучения. 
Компетенции являются результатом деятельности обучающегося [3], при таком обучении приоритет отдается тем учебным задачам, которые воспитывают у студентов готовность к применению полученных знаний, умений и навыков в своей будущей профессиональной деятельности. В общем виде такие задачи должны быть направлены на системное восприятие и овладение способами действия в конкретной производственной ситуации. На наш взгляд, такую роль может выполнять система «сквозных» задач, которая является неким примером, где условия проходят через все темы учебной дисциплины.

Применение подобного рода задач способствует реализации принципов проблемного обучения в высшей школе, позволяет формировать не только познавательные, но и профессиональные мотивы и интересы, воспитывать системное мышление, создавать целостное представление о профессиональной деятельности [4]. Сквозное обучение признается действенным методическим приемом и применяется для активации и актуализации процесса обучения в практике профессионального образования многих учебных заведений [5-9].

Отбор содержания задач должен быть осуществлен с учетом принципов связующей, практико-востребованной, индивидуально-ориентированной, информационно-технологической направленностей деятельности [10]. Возможность ориентировать учебный процесс на развитие профессиональных компетенций была реализована в рамках курса «Предметно-ориентированные экономические информационные системы» для бакалавров направления «Прикладная информатика» профильной подготовки «Прикладная информатика в экономике».

Цель курса: формирование системы знаний в области теории и практики применения экономических информационных систем, изучение теоретических основ создания, структуры, принципов и особенностей функционирования современных предметноориентированных экономических информационных систем. В рамках дисциплины предполагается изучение различных информационных систем: бухгалтерских, банковских, систем управления персоналом [11; 12]. Изучение каждого вида информационных систем организовано в отдельном модуле курса. В качестве примера рассмотрим модуль «Информационные системы управления персоналом».

В рамках этого модуля рассматриваются возможности автоматизации кадрового и расчетного документооборота средствами прикладного решения «Зарплата и управление персоналом» системы «1С:Предприятие». Типовая конфигурация «1С:Зарплата и управление персоналом» позволяет в комплексе автоматизировать задачи, связанные с расчетом заработной платы персонала и реализацией кадровой политики, с учетом требований законодательства и реальной практики работы предприятий, что определяет целесообразность ее использования при изучении курса.

Преемственность и связь в изучении всех разделов модуля обеспечена системой сквозных задач. Описываемая система содержит несколько «сюжетных» линий, демонстрирующих методики учета стандартных операций по ведению кадрового документооборота и управлению персоналом предприятия, расчету и выплате заработной платы [13; 14].

Темы модуля и соответствующие примеры задач представлены в таблице 1.

Представленный пример демонстрирует лишь одну «сюжетную» линию учета. Для заданного сотрудника был полностью организован кадровый и расчетный учет. При оформлении трудовых отношений выбран конкретный график работы и система оплаты труда, зарегистрированы в системе сведения о временной нетрудоспособности, в процессе учета изменена форма оплаты труда, начислены заработная плата и взносы. Ведение других «сюжетных» линий (других сотрудников), параллельно с представленной, позволит продемонстрировать другие особенности кадрового и расчетного учета. Скажем, можно определить другие системы оплаты труда, другие графики работы, ввести другие документы-отклонения (командировка, отпуск ежегодный, невыход по невыясненной причине и т.д.) и проанализировать, каким образом это отражается на суммах начисленной заработной платы.

Применение системы сквозных задач способствует развитию целостного мышления у студентов, приобретению навыков причинно-следственных связей в организации учета предприятия, навыков оценки производственной ситуации [15].

Несмотря на положительные стороны технологии сквозных задач, ее применение сопряжено с рядом определенных трудностей. Опыт работы позволил выделить несколько, вместе с тем для каждой существуют пути решения.

1. Применяемая методика должна быть строго последовательной.

Выполнение заданий координирует преподаватель. Важно, чтобы студенты выполняли задания в установленные сроки. Студент, по какой-либо причине пропустивший хотя бы одну тему, уже не может приступить к выполнению следующей. Он должен в индивидуальном порядке изучить пропущенную тему.

2. Расхождение в скорости выполнения заданий студентами.

В определенный момент времени начинает наблюдаться некоторое расхождение по количеству выполненных заданий между студентами. При решении этой проблемы можно добавить более способным студентам еще одну-две «сюжетные линии», которые не влияют на ход выполнения основных.

3. В некоторых случаях невозможно включить определенного вида задачи, выходящие за рамки решения системы сквозных задач.

По возможности создать систему сквозных задач, максимально отражающую все аспекты учета. В случае, если рассмотрение одной задачи исключает другую, выбрать наиболее сложную. Например, на предприятии может учитываться или не учитываться история изменения штатного расписания. Безусловно, вариант, когда кадровые документы автоматически проверяются на соответствие штатному расписанию в разрезе дат является более сложным, поэтому именно он и должен быть включен в систему сквозных задач. 
Васева Е.C.

Система сквозных задач как условие профессиональной ориентации..

13.00 .00 - педагогические науки

4. Зависимость от результата, полученного на щих заданий. Поэтому обязательным условием запредыдущих этапах.

Студенты на протяжении всех занятий работают с одной информационной базой, поэтому, если возникает ситуация ее утраты или нарушения ее целостности, это делает невозможным выполнение следуювершения работы по каждой теме является создание страховой копии информационной базы и сохранение ее не только на учебном компьютере, но и на внешнем носителе.

Таблица 1 - Фрагмент системы сквозных задач

\begin{tabular}{|c|c|c|c|}
\hline $\begin{array}{c}\text { № } \\
\text { П/П. }\end{array}$ & Тема & Пример задания & $\begin{array}{c}\text { Организация связи } \\
\text { с другими темами модуля }\end{array}$ \\
\hline 1 & $\begin{array}{l}\text { Начало работы } \\
\text { с программным } \\
\text { комплексом } \\
\text { «1С: Предприя- } \\
\text { тие» }\end{array}$ & $\begin{array}{l}\text { Создать информационную базу на ос- } \\
\text { новании шаблона типовой конфигура- } \\
\text { ции, определить пользователей, назна- } \\
\text { чить каждому права }\end{array}$ & $\begin{array}{l}\text { Выполнение последующих заданий по } \\
\text { обеспечению кадрового и расчетного доку- } \\
\text { ментооборота идет от имени пользователей } \\
\text { конфигурации. Неправильное определение } \\
\text { прав пользователя может привести к недо- } \\
\text { ступности объектов системы, необходимых } \\
\text { для осуществления учета }\end{array}$ \\
\hline 2 & $\begin{array}{l}\text { Начало работы с } \\
\text { конфигурацией } \\
\text { «1С:3арплата и } \\
\text { управление пер- } \\
\text { соналом» }\end{array}$ & $\begin{array}{l}\text { Настроить конфигурацию в соответ- } \\
\text { ствии с учетной политикой организа- } \\
\text { ции }\end{array}$ & $\begin{array}{l}\text { При изучении темы выполняется определе- } \\
\text { ние параметров, которые влияют на работу } \\
\text { всей конфигурации }\end{array}$ \\
\hline 3 & $\begin{array}{l}\text { Настройка } \\
\text { графиков } \\
\text { работы }\end{array}$ & $\begin{array}{l}\text { Определить в системе график работы, } \\
\text { соответствующий пятидневной, } 40 \text {-ча- } \\
\text { совой рабочей неделе, в расписании } \\
\text { графика учитываются праздничные дни }\end{array}$ & $\begin{array}{l}\text { Учет отработанного времени определяется } \\
\text { из графика работы сотрудника и влияет на } \\
\text { расчет заработной платы }\end{array}$ \\
\hline 4 & $\begin{array}{l}\text { Штатно- } \\
\text { должностная } \\
\text { структура } \\
\text { организации }\end{array}$ & $\begin{array}{l}\text { Сформировать штатное расписание ор- } \\
\text { ганизации на данную дату согласно } \\
\text { условиям }\end{array}$ & $\begin{array}{l}\text { Если в конфигурации установлен признак } \\
\text { «вести контроль штатного расписания», по- } \\
\text { следующий прием на работу будет осу- } \\
\text { ществляться строго в соответствии с ним }\end{array}$ \\
\hline 5 & $\begin{array}{l}\text { Учет } \\
\text { персональных } \\
\text { данных }\end{array}$ & $\begin{array}{l}\text { Внести в конфигурацию персональные } \\
\text { данные физического лица: ФИО, дата } \\
\text { рождения, пол, ИНН, номер СНИЛС, } \\
\text { сведения о гражданстве и т.д. }\end{array}$ & $\begin{array}{l}\text { В конфигурации обеспечивается хранение } \\
\text { персональных данных физических лиц, ко- } \\
\text { торые будут необходимы для выполнения } \\
\text { регламентированных расчетов }\end{array}$ \\
\hline 6 & $\begin{array}{l}\text { Системы } \\
\text { оплаты } \\
\text { труда }\end{array}$ & $\begin{array}{l}\text { Добавить новый вид премиального } \\
\text { начисления - Фиксированный процент } \\
\text { с выручки. Итоговая сумма начисления } \\
\text { должна определяться процентом, вве- } \\
\text { денном при приеме на работу сотруд- } \\
\text { ника, и размером выручки }\end{array}$ & $\begin{array}{l}\text { Система оплаты труда задается для данного } \\
\text { сотрудника при приеме на работу }\end{array}$ \\
\hline 7 & $\begin{array}{l}\text { Оформление } \\
\text { трудовых } \\
\text { отношений }\end{array}$ & $\begin{array}{l}\text { Оформить трудовой договор и приказ } \\
\text { о приеме на работу на физическое ли- } \\
\text { цо }\end{array}$ & $\begin{array}{l}\text { При оформлении документов выбирается } \\
\text { уже зарегистрированное ранее (тема 5) фи- } \\
\text { зическое лицо. В качестве кадровых данных } \\
\text { выбираются график работы (тема 3) и си- } \\
\text { стема оплаты труда (тема 6). При проведе- } \\
\text { нии документа происходит его проверка на } \\
\text { соответствие штатному расписанию (тема 4) }\end{array}$ \\
\hline 8 & $\begin{array}{l}\text { Кадровые доку- } \\
\text { менты }\end{array}$ & $\begin{array}{l}\text { Составить график отпуска для данного } \\
\text { сотрудника организации }\end{array}$ & $\begin{array}{l}\text { При составлении графика учитывается срок } \\
\text { работы в организации, а также возможность } \\
\text { получения дополнительного отпуска (тема 7) }\end{array}$ \\
\hline 9 & $\begin{array}{l}\text { Данные } \\
\text { для расчета } \\
\text { заработной } \\
\text { платы }\end{array}$ & $\begin{array}{l}\text { Оформить больничный лист на со- } \\
\text { трудника согласно заданным условиям }\end{array}$ & $\begin{array}{l}\text { При расчете больничного листа учитывают- } \\
\text { ся сведения о стажах сотрудника (темы } 5 \text { и } \\
\text { 7). Количество фактически отработанных } \\
\text { дней определяется нормой времени в днях } \\
\text { (тема 3) и количеством дней-отклонений }\end{array}$ \\
\hline 10 & $\begin{array}{l}\text { Начисление } \\
\text { заработной } \\
\text { платы }\end{array}$ & $\begin{array}{l}\text { Начислить заработную плату и взносы } \\
\text { сотруднику организации за определен- } \\
\text { ный месяц }\end{array}$ & $\begin{array}{l}\text { При начислении заработной платы учиты- } \\
\text { ваются все сведения, зарегистрированные в } \\
\text { системе, начиная с ввода персональных } \\
\text { данных и заканчивая оформлением доку- } \\
\text { ментов-отклонений }\end{array}$ \\
\hline
\end{tabular}


Все обозначенные трудности являются вполне преодолимыми, а способы их разрешения позволяют студентам еще в большей степени получить определенный опыт решения профессиональных задач, возникающих в повседневной деятельности работников организации, занимающих различные должности. Система сквозных задач позволяет в некоторой степени погрузить студента в его будущую профессиональную деятельность, ведь любая производственная ситуация - это не независимая задача, и ее решение требует знания условий, которые, может быть, «происходили вчера» или «наступят только завтра».

Выполнение системы сквозных задач позволяет студентам оценивать производственную ситуацию целостно, диагностировать и корректно исправлять пользовательские ошибки в информационной базе, использовать нормативно-правовую базу, относящуюся к будущей профессиональной деятельности.

\section{СПИСОК ЛИТЕРАТУРЫ:}

1. Федеральный закон «Об образовании в Российской Федерации» от 29.12.2012 № 273-Ф3 (действующая редакция, 2016).

2. Приказ Минобрнауки России от 12.03.2015 № 207 «Об утверждении государственного образовательного стандарта высшего образования по направлению подготовки 09.03.03 Прикладная информатика (уровень бакалавриата)».

3. Шишов С.Е., Кальней В.А., Бухтеева Е.В. Проблема формирования компетенций методическими средствами в процессе обучения // Вестник РМАТ. Педагогика профессионального образования. 2014. № 1(10). С. 73-78.

4. Вербицкий А.А. Активное обучение в высшей школе: контекстный подход: метод. пособие. М.: Высшая школа, 1991. 207 с.

5. Акишина О.Н. Сквозная профессиональная задача как элемент технологии проблемного обучения // Профессиональное образование и общество. 2014. № 1 (10). С. 150-152.

6. Баранов А.В. Обучение компьютерному моделированию механического движения в Mathcad на системе «сквозных» задач (Ч. 1) // Дистанционное и виртуальное обучение. 2014. № 11(89). С. 98-109.

7. Надеждин А.В. Метод сквозного обучения теоретической и прикладной механике для студентов специальности «Архитектура» // Перспективы развития строительного комплекса. 2012. Т. 1. С. 12-15.

8. Петрова Л.Л., Труфанова Л.В. Экологические вопросы - сквозная тема обучения на кафедре биохимии // Инновационные педагогические технологии в медицинском образовании. Вузовская педагогика: мат-лы конф. Красноярск: Версо, 2010. С. 336-338.

9. Семкина Е.В. Формирование компетенций у учащихся бухгалтерско-экономических специальностей колледжей при изучении автоматизированного бухгалтерского учета // Вестник Омского регионального института. 2015. Т. 1. № 1-1. С. 123-127.

10. Вахрушева Н.В. «Сквозные» задачи как средство совершенствования математической подготовки бакалавров-экономистов // Известия Волгоградского государственного педагогического университета. 2012. № 5(69). С. 87-91.

11. Бодров О.А. Предметно-ориентированные экономические информационные системы / под ред. О.А. Бодрова, Р.Е. Медведева. М.: Горячая линияТелеком, 2013. 244 с.

12. Вдовин В.М. Предметно-ориентированные экономические информационные системы: учебное пособие / под ред. В.М. Вдовина, Л.Е. Сурковой, А.А. Шурупова. М.: Дашков и К, 2012. 388 с.

13. Грянина Е.А., Харитонов С.А. Настольная книга по оплате труда и ее расчету в «1С:Зарплата и управление персоналом 8» (ред. 3.0). М.: ООО «1СПаблишинг», 2015. 614 с.

14. Грянина Е.А., Харитонов С.А. Секреты профессиональной работы с «1С:Зарплата и Управление Персоналом 8». Кадровый учет и управление персоналом. М.: ООО «1С-Паблишинг», 2010. 510 с.

15. Садчикова О.А., Протопопова Н.Е. Формирование практических навыков у студентов посредствам сквозной задачи по дисциплине «Аудит» // Экономика и бизнес. 2015. № 2. С. 57-60.

\section{CROSS-CUTTING TASKS SYSTEM AS A CONDITION OF PROFESSIONAL TRAINING ORIENTATION OF STUDENTS MAJORING IN «APPLIED INFORMATION TECHNOLOGIES»}

Vaseva Elena Sergeevna, candidate of pedagogical sciences, associate professor of Information Technologies Department Nizhny Tagil State Institute of Social Sciences and Education (branch of Russian State Vocational Pedagogical University) (Nizhny Tagil, Sverdlovsk Region, Russian Federation)

Abstract. The paper deals with the cross-cutting tasks system use for the university education as a necessary condition of professional education orientation. The application of the cross-cutting tasks system promotes holistic students' thinking and helps to master the means of action in a particular work situation. The paper contains a fragment of the system developed by the author for the course «Subject-oriented economic information systems» for bachelor students majoring in «Applied Information Technologies in Economics». The course consists of several modules, the cross-cutting tasks system is used in the module «Information systems of personnel management». The fragment of the system contains multiple «plot» lines that show methods of standard operations for personnel documents maintaining and enterprise personnel management, calculation and salary payment in the automated system. Specific tasks help to demonstrate continuity and connectivity of all sections in the module. The author of the paper considers some difficulties of the cross-cutting tasks system application: strict sequence of the methodology; difference in time that students need to perform the tasks; inability to include some tasks in the system; dependence on the results obtained during previous classes. The paper also contains possible ways of overcoming these difficulties.

Keywords: system of cross-cutting tasks; training; academic discipline; system perceptions; professional competence; applied learning; particular work situation; subject-oriented economic information system; information system of personnel management. 